\title{
Decompressive craniectomy after traumatic brain injury: a systematic review of recent evidences
}

\author{
Lorenzo Marocchi*, Valeria Spennati ${ }^{\star}$, Marco Cinicola*, Anna Prete*, Ilaria Caiazzo*, \\ Fabrizio Caroletti*, Daria Collacchi* \\ Affiliation: *Sapienza University of Rome, Dept. of Anaesthesiology \& Critical Care, \\ Rome, Italy
}

The role of decompressive craniectomy (DC) in the treatment of patients with high intracranial pressure (hICP) after traumatic brain injury (TBI) is controversial. Aim of this systematic review (SR) is to summarize recent clinical evidences on DC in hICP after TBI.

A systematic literature search of PubMed using (brain injury) AND (DC) and (brain injury) AND (ICP) as key words of papers published between January 2011 to November 2016, has been accomplished. Only full text papers published in English and presenting original data were included. The articles were evaluated according to PRISMA recommendations and details recorded using a dedicated data extraction form.

This SR, includes 4 studies: 2 RCTs ( $\mathrm{n}=553$ patients) and 2 observational ( $\mathrm{n}=627$ patients). The 2 RCTs report partially conflicting results. ${ }^{1,2}$

The DECRA trial, tested early DC for hICP management and showed a better control of ICP in DC group vs. medical therapy group $(14.4 \mathrm{mmHg}$ vs. $19.1 \mathrm{mmHg}, \mathrm{P}<0.001)$.

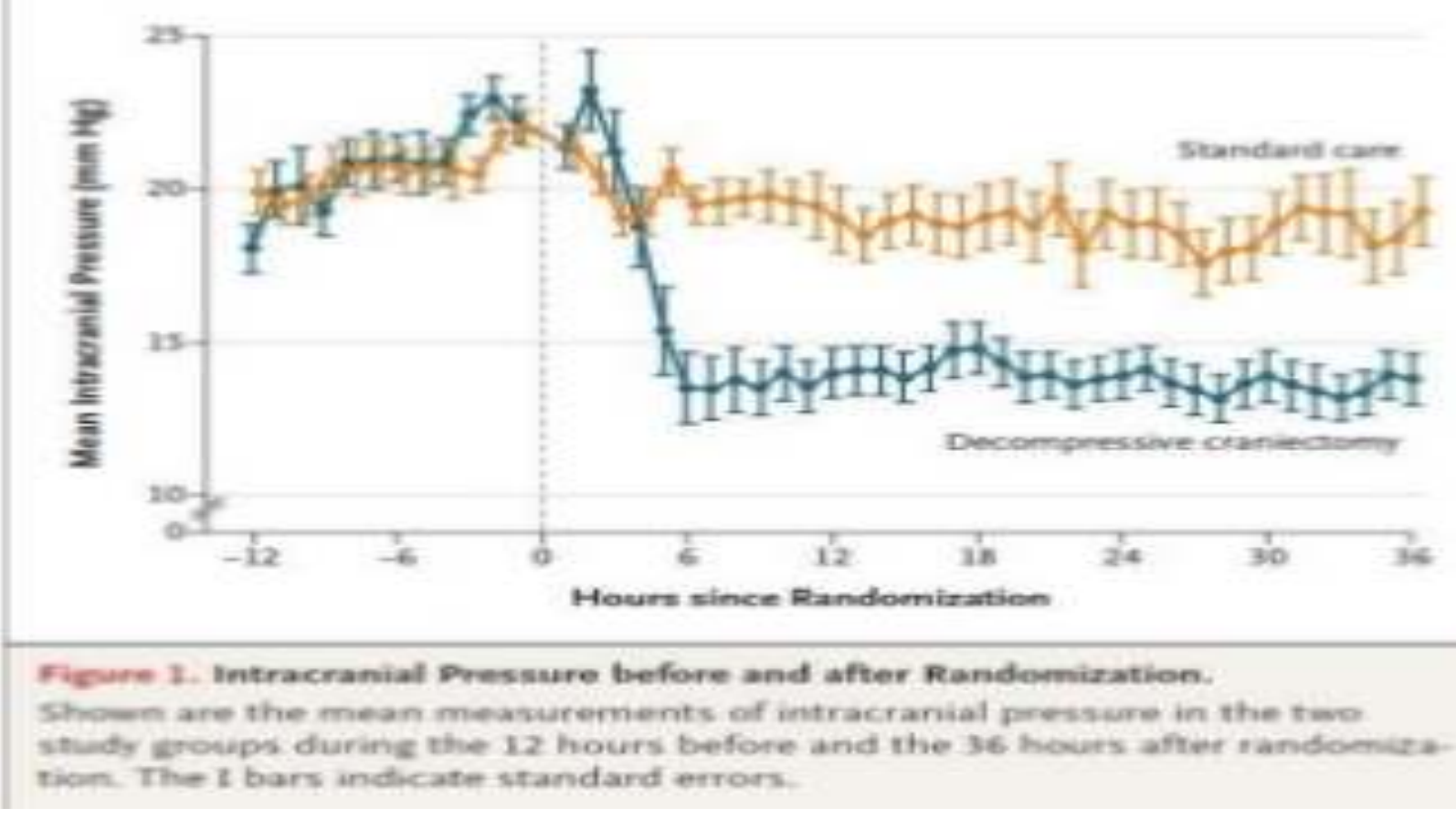

Paradoxically, better ICP control was associated with higher unfavorable outcomes (GOS-E 1-4 70\% vs. $51 \%$; OR $2.21 ; 95 \% \mathrm{CI}, 1.14$ to $4.26 ; \mathrm{P}=0.02$ ) and worse functional outcome (6 months GOS-E median score, 3 vs. 4; OR 1.84; 95\% confidence interval [CI], 1.05 to $3.24 ; \mathrm{P}=0.03)$.

\section{References:}

1.- Cooper DJ. NEJM 2011;364(16):1493-502.

2.- Hutchinson PJ. NEJM 2016;375(12):1119-30.

3.- Fotakopoulos G. According to which factors in severe TBI craniectomy could be beneficial. Surg Neurol Int 2016;7:19

4.- Tagliaferri F. Acta Neurochir (Wien) 2012; 154: 919-26.

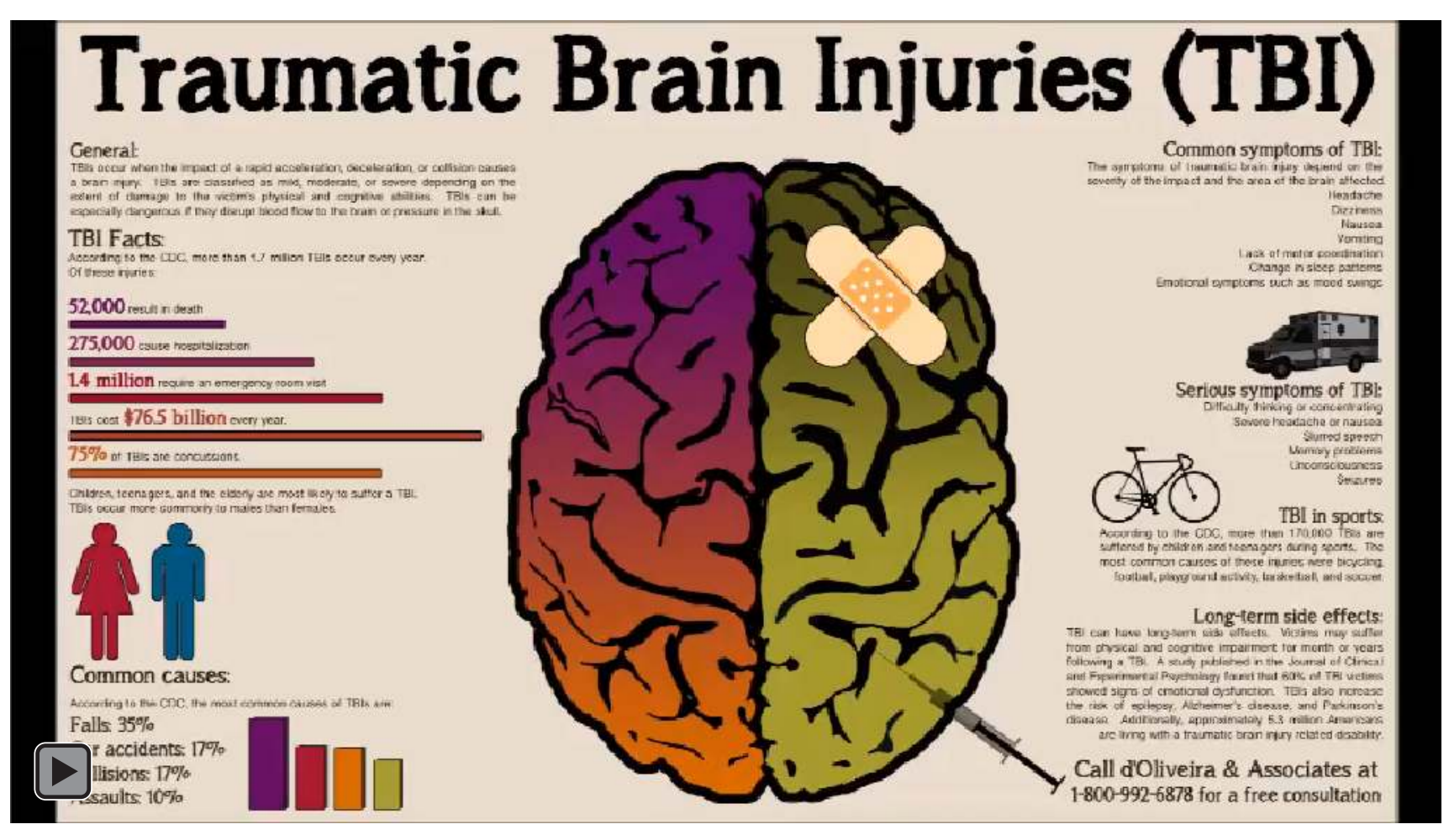

The RESCUEicp trial, tested DC as a last tier therapy for hICP, and reported lower mortality in DC group than in control $(26.9 \%$ vs. $48.9 \%$; $\mathrm{P}<0,001)$. Of interest, GOS-E at 12 months, confirmed the clinical benefit associated with DC: a higher rate of patients treated with DC had higher "upper severe disability good recovery" at follow up than the control group $(45,4 \%$ vs. $32,4 \% ; \mathrm{P}=0,01)$.

The 2 observational studies reported an association between good outcome and: age $<60$, early timing (DC when ICP $<20 \mathrm{mmHg}$ ), bone flap $>130 \mathrm{~cm} 2$, and GCS $>5$ before DC. 3,4

The benefit of DC remains controversial but recent evidence displayed positive results. Optimal timing and presence of prognostic parameters are associated with better outcome. Indiscriminate application of DC is not appropriate and possible clinical benefit deserve specific circumstances and pts selection.

\begin{tabular}{|c|c|c|c|c|}
\hline $\begin{array}{c}\text { GOSE } \\
\text { CATEGORY }\end{array}$ & SCORE & $\begin{array}{c}\text { GOS } \\
\text { CATEGORY }\end{array}$ & SCORE & $\begin{array}{l}\text { DICHOTOMISED } \\
\text { SCORE }\end{array}$ \\
\hline Dead & 1 & Dead & 1 & \multirow{4}{*}{ Unfavourable } \\
\hline Vegetative state & 2 & Vegetative state & 2 & \\
\hline Lower severe disability & 3 & & & \\
\hline Upper severe disability & 4 & Severe disability & 3 & \\
\hline $\begin{array}{l}\text { Lower moderate } \\
\text { disability }\end{array}$ & 5 & \multirow[b]{2}{*}{ Moderate Disability } & \multirow[b]{2}{*}{4} & \multirow{4}{*}{ Favourable } \\
\hline $\begin{array}{l}\text { Upper moderate } \\
\text { Disability }\end{array}$ & 6 & & & \\
\hline Lower good recovery & 7 & & & \\
\hline Upper good recovery & 8 & Good recovery & 5 & \\
\hline
\end{tabular}

EXTENDED GLASGOW OUTCOME SCORE

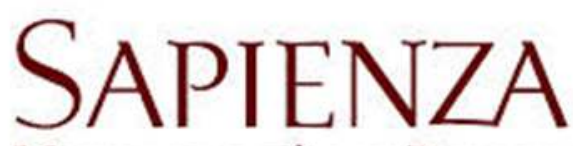

UNIVERSITÀ DI ROMA 